\title{
Mamdani and Sugeno Fuzzy Performance Analysis on Rainfall Prediction
}

\section{| Yuan Ardi ${ }^{1{ }^{*}}$ | Syahril Effendi ${ }^{2}$ | Erna Budhiarti Nababan ${ }^{3}$ |}

1,2,3 Departement of Computer Science, Universitas Sumatera Utara, Medan, Indonesia

*u1ardhieee77@gmail.com

\begin{abstract}
Fuzzy logic is an extension of traditional reasoning, where $x$ is a member of set $A$ or not, or an $x$ can be a member of set $A$ with a certain degree of membership $(\mu)$. The ability of fuzzy models to map fuzzy values is the reason for using fuzzy inference models in various cases that use fuzzy values to produce a clear or definite output. In this research, an analysis of the level of accuracy generated by the Sugeno and Mamdani inference model will be carried out in predicting rainfall at Polonia Station, Medan, North Sumatra. Prediction results will be analyzed for accuracy by comparing the results obtained by Sugeno fuzzy inference models and Mamdani using Mean Absolute Percent Error (MAPE). When compared to the results of the Mean Absolute Percent Error (MAPE) Sugeno fuzzy inference model of $1.33 \%$ and mamdani fuzzy inference model of $1.45 \%$, then the accuracy rate for the Sugeno inference model is $100 \%-1.33 \%=98.67 \%$ while the Mamdani fuzzy inference model is $100 \%-1.45=98.55 \%$. The end result is that the membership function model used in the Sugeno fuzzy model is more accurate than the Mamdani fuzzy inference model in the test case of rainfall prediction at Polonia station in Medan. North Sumatra. The results of the analysis carried out for the Sugeno and Mamdani fuzzy models are influenced by the accuracy of the input values. Rainfall prediction is an important thing to study, weather conditions in certain areas can be predicted so that it can help people's daily activities, can determine a series of community social activities. For example, information on rainfall and its classification is widely used as a guide for agriculture, tourism and transportation, for example: Cropping Patterns, Harvest Predictions, Shipping and flight schedules

KEYWORDS

Sugeno rediction; Mamdani; accuracy; analysis; MAPE; Matlab2016a; social activities
\end{abstract}

\section{INTRODUCTION}

Precipitation is a complex and most difficult element of the hydrological cycles. Rainfall trends and forecasts are very high, difficult to understand and model due to the complexity of the atmospheric processes that produce rainfall (Jignesh et.al.2014). Rainfall is an important factor in agricultural countries, such as Indonesia. Prediction of rainfall is very important for science, both scientifically and technologically.

Various methods of forecasting rainfall are available. There are mainly two approaches to predicting rainfall (Jyothis et.al.2013), namely the Empirical Method and the Dynamic Method. The Empirical Method approach is based on the analysis of historical rainfall data and their relationship to various atmospheric and marine variables in various parts of the world. Empirical method approaches that are most widely used for climate prediction are 
Regression, Artificial Neural Networks (ANN), Fuzzy Logic, Genetic Algorithms and Hybrid Methodologies. Such as the study of Fallah Ghalhary et.al (2009) which uses Mamdani fuzzy logic with promise with RMSE efficiency of 52. Further research by Mayilvaganan et.al (2011) which produces a good output with R and RMSE values on the Neural Network Algorithm is better than fuzzy logic. However, some problems such as the difficulty of selecting the expected rainfall estimation parameters, this must be done repeatedly so that the accuracy results are small. So that another approach is needed to minimize errors and speed up the ability to predict rainfall and make computations lighter to produce forecasting values with the best accuracy.

In order for this research to be directed, several limitations were carried out, namely the method used was the Sugeno and Mamdani Fuzzy Inference System using the MATLAB R2016a software as a test tool. Observing and testing the Sugeno and Mamdani Fuzzy Inference System Algorithm to get the smallest Error Value obtained in the Rainfall Prediction results using atmospheric parameters including Wind Speed, Visibility, Dew Point and Temperature, based on the results of the calculation of the absolute average error. Mean Absolute Percent Error (MAPE), MAPE will measure the accuracy of forecasting results generated by a Forecast model. The purpose of this research is to analyze the correct algorithm and the values that influence and produce a better error value in a rainfall prediction.

\section{LITERATURE REVIEW}

Fuzzy Logic Systems (FLS) is basically a multi-valued logic, which allows intermediate value positions to be defined between conventional evaluations such as big and small, fast or slow, near or far etc. A way to map input problems to expected outputs can be done by fuzzy logic method. as well as estimation which is a picture/prediction in the future which will be known to happen with a better level of accuracy.

According to Hoseein Zadeh et.al (2011) that fuzzy logic is often used in intelligent systems to sort out processes/detect defects in their implementation. Nasution (2012) linguistically states that fuzzy logic is fuzzy or vague.

Cox (1994) explains that the considerations of using fuzzy logic, among others, are easy to understand, flexible, have the ability to handle inaccurate data, are able to model complex nonlinear functions, can build and apply the experience of experts directly without having to go through the training process, can work together. with conventional control techniques, everyday hope so that it is quickly understood.

Fuzzy logic is a logic that has a value of fuzziness between true and false. In fuzzy logic theory a value can be true or false together. However, how big the presence and error of a product depends on the weight of its membership. Nasution (2012) linguistically states that fuzzy logic is fuzzy or vague.

According to Cox (1994), there are several reasons why people use fuzzy logic, including:

a. The concept of fuzzy logic is easy to understand, because fuzzy logic uses the basis of set theory, the mathematical concepts underlying fuzzy reasoning are quite easy to understand.

b. Fuzzy logic is very flexible, meaning that it is able to adapt to changes and uncertainties that accompany problems.

c. Fuzzy logic has tolerance for imprecise data. If given a group of homogeneous data, and then there are some that are exclusive, then fuzzy logic has the ability to handle that exclusive data.

d. Fuzzy logic is able to model very complex nonlinear functions. 
e. Fuzzy logic can build and apply the experiences of experts directly without having to go through the training process. In this case, often known as fuzzy expert systems, it is the most important part.

f. Fuzzy logic can work with conventional control techniques. This generally occurs in applications in mechanical engineering and electrical engineering. Fuzzy logic is based on natural language. Fuzzy logic uses everyday language so it is easy to understand.

\section{RESEARCH METHODS}

Fuzzy logic is the development of monotonous reasoning, in this chapter the author describes all the methodologies used to solve this research problem using Sugeno and Mamdani's fuzzy inference model.

The flow of research methodology, defined about the chart of the research and testing process:

a. In the early stages of selecting the dataset, this study used data sources taken from http://www7.ncdc.noaa.gov/cdo. based on the dataset criteria at the Polonia station in Medan, North Sumatra and has been converted into Indonesian climate units. Furthermore, the data is identified and classified according to the group, determines the validity of the data and variables that will be used after that initialization of the data is used as a fuzzy variable interval as the basis for making fuzzification.

b. Furthermore, the data will be fuzzified, each fuzzy variable in the input data will be divided into 3 (three) fuzzy sets, namely low, medium and high. All fuzzy sets and each fuzzy variable in the input data will be represented using a membership function, namely in the form of a descending linear curve, a trapezoid and an ascending linear curve. Then from fuzzification, the data is processed using the specified model, namely Mamdani and Sugeno in order to produce the basic rules of the fuzzy inference model.

c. Finally, the process results from the mamdani and Sugeno inference methods are fuzzy numbers (fuzzy) which will then be returned to firm numbers (scrisp) by defuzzification, and produce output in the form of predictions of rainfall which will be compared with the actual value to see the accuracy of predictions from the Sugeno and Mamdani models

\section{RESULTS AND DISCUSSION}

From the data modeling process, inference and accuracy results from the two inference models Sugeno and Fuzzy Mamdani in predicting rainfall at Polonia Station, Medan, North Sumatra.

\section{Fuzzy basic rules}

There are 4 (four) input variables with each having 3 (three) sets, namely wind speed, visibility, dew point and temperature, the output variable is rainfall variable. variables and fuzzy sets as shown in table 1 . Set variable

Table 1. Set Variables

\begin{tabular}{lll}
\hline No & Input Variable & Set \\
\hline 1 & Wind velocity & Low, Medium and High \\
2 & Visibility & Near, Medium and Far \\
3 & Dew Point & Low, Medium and High \\
4 & Temperature & Cool, Normal and Hot \\
5 & Rainfall & Light, Medium and Dense \\
\hline
\end{tabular}


In a combination of four (4) input variables with three (3) fuzzy sets with $3^{\text {n }}$ equations where $\mathrm{n}$ is the number of variables. From this equation, there are 81 (eighty one) rules for the input variable. The following is the determination of the variables and the universe of conversation as shown in Table 2

Table 2. Universe of talk

\begin{tabular}{|l|l|l|}
\hline Input & Variable & Universe of talk \\
\hline \multirow{4}{*}{ Input } & Wind Speed (km/hour) & {$\left[\begin{array}{ll}3,73 & 8,09\end{array}\right]$} \\
\cline { 2 - 3 } & Visibility $(\mathrm{km})$ & {$\left[\begin{array}{ll}2,65 & 8,57\end{array}\right]$} \\
\cline { 2 - 3 } & Dew Point (c) & {$\left[\begin{array}{ll}22,91 & 25,19\end{array}\right]$} \\
\cline { 2 - 3 } & Temperature (c) & {$\left[\begin{array}{ll}25,84 & 29,06\end{array}\right]$} \\
\hline Output & Rainfall (mm) & {$\left[\begin{array}{ll}0 & 14,71\end{array}\right]$} \\
\hline
\end{tabular}

\section{Determine the membership function of each variable}

a. Variable Wind Speed.

The wind speed variable forms a fuzzy set with the following membership functions:

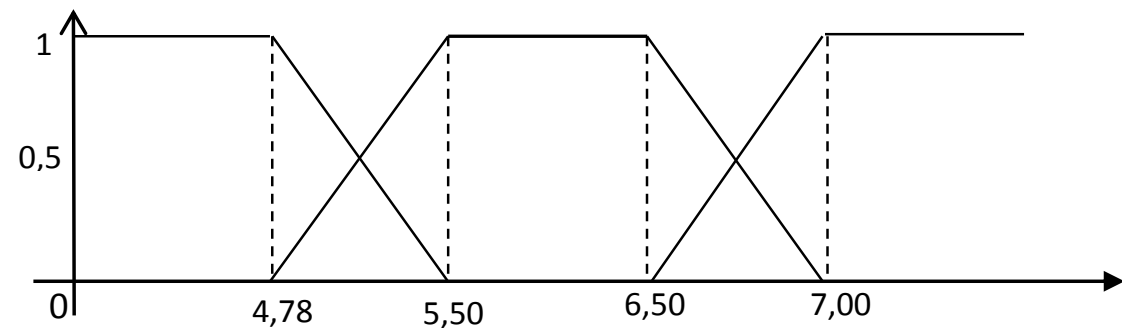

Figure 1. Wind Speed Variable membership function

$$
\begin{gathered}
\mu[\text { Slow }]= \begin{cases}1 ; & x \leq 4,78 \\
\frac{5,50-x}{5,50-4,78} ; & 4,78<x \leq 5,50 \\
0 ; & x \geq 5,50\end{cases} \\
\mu\left[\text { Medium ] }= \begin{cases}0 ; & x \leq 5 \\
\frac{x-4,78}{5,5-4,78} ; & 5 \leq x \leq 5,50 \\
1 ; & 5,5 \leq x \leq 6,5 \\
\frac{7-x}{7-6,5} ; & 6,5 \leq x \leq 7 \\
0 ; & x \geq 7\end{cases} \right. \\
\mu\left[\text { Fast ] }=\left\{\begin{array}{cl}
0 ; & x \leq 6,5 \\
\frac{x-6,5}{7-6,5} ; & 6,5 \leq x \leq 7 \\
1 ; & x \geq 7
\end{array}\right.\right.
\end{gathered}
$$

b. Visibility Variable.

Visibility varjable forms a fuzzy set with the following membership functions:

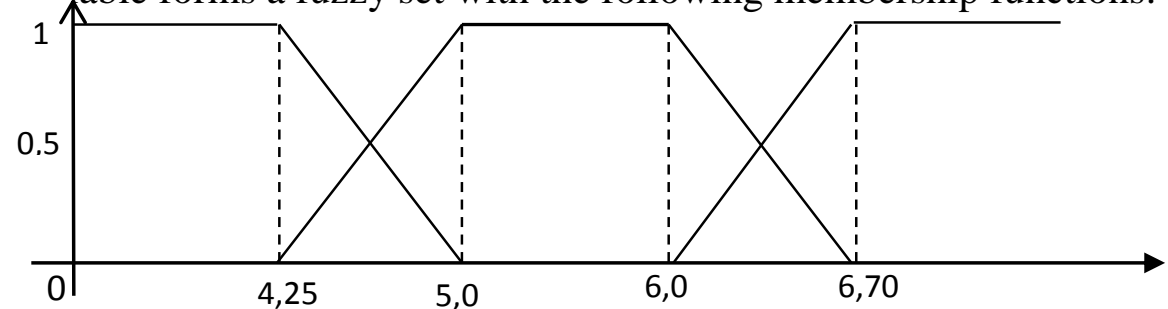

Figure 2. Membership Function Curve Visibility 


$$
\begin{aligned}
& \mu[\text { Near }]= \begin{cases}1 ; & x \leq 4,25 \\
\frac{5-\mathrm{x}}{5-4,25} ; & 4,25<x \leq 5 \\
0 ; & x \geq 5\end{cases} \\
& \boldsymbol{\mu} \text { [ Medium ] }=\left\{\begin{array}{lc}
0 ; & 5 \leq x \leq 6 \\
\frac{\mathrm{x}-4,25}{5-4,25} ; & 4,25 \leq x \leq 5 \\
1 ; & 5 \leq x \leq 6 \\
\frac{6,7-x}{6,7-6} ; & 6 \leq x \leq 6,7 \\
0 ; & x \geq 6,7
\end{array}\right. \\
& \mu[\text { Far }]=\left\{\begin{array}{cl}
0 ; & x \leq 6 \\
\frac{x-6}{6,7-6} ; & 6 \leq x \leq 6,7 \\
1 ; & x \geq 6,7
\end{array}\right.
\end{aligned}
$$

c. Dew Point Variable.

The Dew Point variable forms a fuzzy set with the following membership functions:

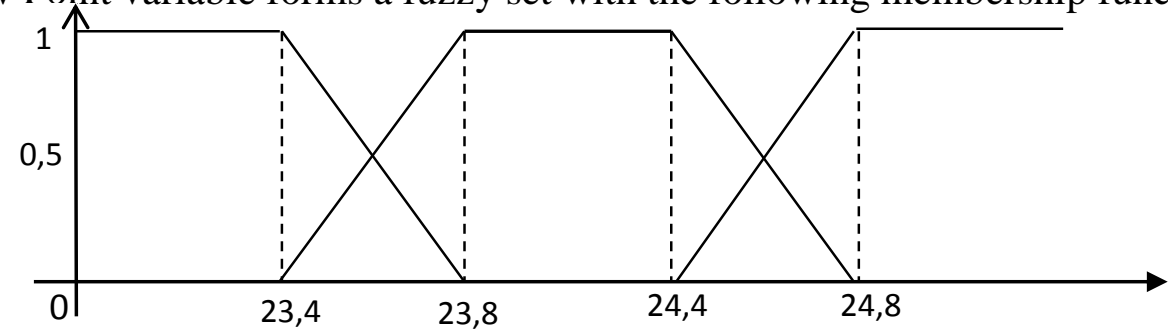

Figure 3. Dewpoint Variable Membership Function Curve

$$
\begin{aligned}
& \mu[\text { Low }]= \begin{cases}1 ; & x \leq 23,40 \\
\frac{23,80-x}{23,80-23,40} ; & 23,40<x \leq 23,80 \\
0 ; & x \geq 23,80\end{cases} \\
& \mu\left[\text { Medium ] }=\left\{\begin{array}{cl}
0 ; & x \leq 23,60 \\
\frac{\mathrm{x}-23,40}{23,80-23,40} ; & 23,60 \leq x \leq 23,80 \\
1 ; & 23,80 \leq x \leq 24,40 \\
\frac{24,80-\mathrm{x}}{24,80-24,40} ; & 24,40 \leq x \leq 24,60 \\
0 ; & x \leq 24,60
\end{array}\right.\right. \\
& \mu \text { [ High ] }=\left\{\begin{array}{cc}
0 ; & x \leq 24,40 \\
\frac{\mathrm{x}-24,40}{24,80-24,40} ; & 24,40 \leq x \leq 24,80 \\
1 ; & x \geq 24,80
\end{array}\right.
\end{aligned}
$$

d. Variable Temperature

The temperature variable forms a fuzzy set with the following membership functions:

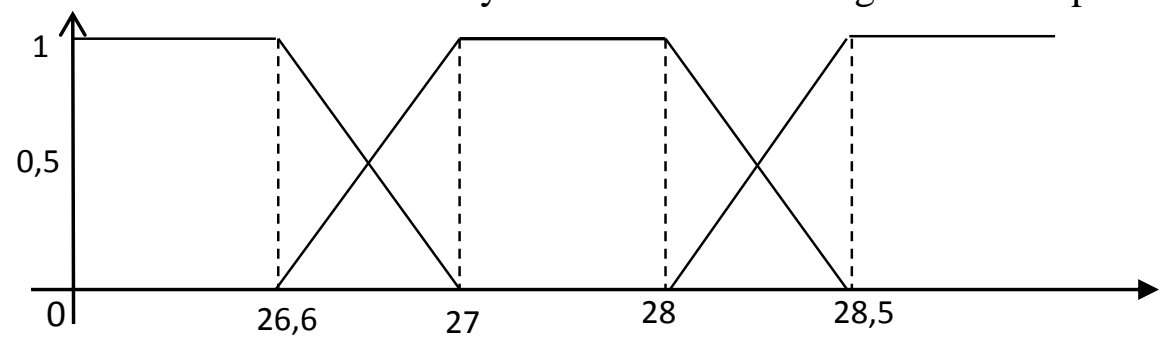

Figure 4. Temperature Variable Membership Function Curve 


$$
\begin{aligned}
& \mu[\mathrm{Cool}]= \begin{cases}1 ; & 27-\mathrm{x} \\
\frac{27-26,60}{27} ; & 26,60<x \leq 27 \\
0 ; & x \geq 27\end{cases} \\
& \mu[\text { Normal }]= \begin{cases}0 ; & x \leq 26,60 \\
\frac{\mathrm{x}-26,60}{27-26,60} ; & 26,60 \leq x \leq 27 \\
1 ; & 27 \leq x \leq 28 \\
\frac{28,50-\mathrm{x}}{28,50-28} ; & 28 \leq x \leq 28,50 \\
0 ; & x \leq 28,50\end{cases} \\
& \mu[\text { Hot }]= \begin{cases}0 ; & x \leq 28 \\
\frac{\mathrm{x}-28}{28,50-28} ; & 28 \leq x \leq 28,50 \\
1 ; & x \geq 28,50\end{cases}
\end{aligned}
$$

\section{Fuzzification results of input variables}

Fuzzification will be carried out on the variables of wind speed, visibility, dew point and temperature for the months of January to December 2007 where the fuzzification is in the form of membership degrees with the provision that the results of the membership degrees of the fuzzy set must be added up to 1 then the membership degree is said to be true. This provision applies to all degrees of membership resulting from the input variable. by using a descending linear representation and a trapezoidal representation for the variables of wind speed, visibility, dew point and temperature in January 2007, then the degree of membership in each variable is obtained. For more details, the results of membership degrees for variables of wind speed, visibility, dew point and temperature in January 2007 according to table 3. and so on until the results of the input variable membership degrees in December 2007 according to table 4.

Table 3. Result of membership degree variable Input January 2007

\begin{tabular}{llll}
\hline No. & Fuzzy Variable & Fuzzy Set & Membership Degree \\
\hline 1. & Wind velocity & Slow & 0,70 \\
& & Medium & 0,30 \\
& & Fast & 0 \\
\hline 2. & Visibility & Near & 0 \\
& & Medium & 0,34 \\
& & Far & 0,66 \\
\hline 3. & Dew Point & Low & 0,77 \\
& & Medium & 0,23 \\
& & High & 0 \\
\hline 4. & Temperature & Cool & 0,85 \\
& & Normal & 0,15 \\
& & Hot & 0 \\
\hline
\end{tabular}

Table 4. Result of membership degree variable Input December 2007

\begin{tabular}{llll}
\hline No. & Fuzzy Variable & Fuzzy Set & Membership Degree \\
\hline 1. & Wind velocity & Slow & 0,56 \\
& & Medium & 0,44 \\
& & Fast & 0 \\
\hline 2. & Visibility & Near & 0 \\
& & Medium & 0 \\
& & Far & 1 \\
\hline
\end{tabular}




\begin{tabular}{llll}
\hline 3. & Dew Point & Low & 1 \\
& & Medium & 0 \\
& & High & 0 \\
\hline 4. & Temperature & Cool & 1 \\
& & Normal & 0 \\
& & Hot & 0 \\
\hline
\end{tabular}

\section{Formation of Fuzzy Rulebase (Fuzzy Rulebase)}

After the formation of membership degrees, the basic rules of the Sugeno fuzzy are formed using the Sugeno fuzzy model, in general the Sugeno fuzzy model, in general the form of the zero Sugeno fuzzy model is:

$$
\operatorname{IF}\left(x_{1} \text { is } A_{i}\right) \circ \ldots \circ\left(x_{n} \text { is } A_{n}\right) \text { THEN z }=k
$$

Where A1 is the first fuzzy set as the antecedent, and p1 is the first (firm) constant and q is also a constant in the consequent. Based on the number of four input variables with 3 fuzzy sets each.

Table 5. Rules of the four Input variables

\begin{tabular}{|c|c|c|c|c|c|}
\hline \multirow{2}{*}{ Rules To } & \multicolumn{4}{|c|}{ Rule Base } & \multirow{2}{*}{ Result } \\
\hline & wind_velocity & visibility & dew_point & temperature & \\
\hline 1 & 1 & 1 & 1 & 1 & 1 \\
\hline 2 & 1 & 1 & 1 & 2 & 1 \\
\hline 3 & 1 & 1 & 1 & 3 & 1 \\
\hline 4 & 1 & 1 & 2 & 1 & 1 \\
\hline 5 & 1 & 1 & 2 & 2 & 1 \\
\hline 6 & 1 & 1 & 2 & 3 & 1 \\
\hline 7 & 1 & 1 & 3 & 1 & 1 \\
\hline 8 & 1 & 1 & 3 & 2 & 2 \\
\hline 9 & 1 & 1 & 3 & 3 & 2 \\
\hline 10 & 1 & 2 & 1 & 1 & 2 \\
\hline 11 & 1 & 2 & 1 & 2 & 2 \\
\hline 12 & 1 & 2 & 1 & 3 & 2 \\
\hline 13 & 1 & 2 & 2 & 1 & 2 \\
\hline 14 & 1 & 2 & 2 & 2 & 2 \\
\hline 15 & 1 & 2 & 2 & 3 & 3 \\
\hline 16 & 1 & 2 & 3 & 1 & 3 \\
\hline 17 & 1 & 2 & 3 & 2 & 3 \\
\hline 18 & 1 & 2 & 3 & 3 & 3 \\
\hline 19 & 1 & 3 & 1 & 1 & 3 \\
\hline$\vdots$ & $\vdots$ & $\vdots$ & $\vdots$ & $\vdots$ & $\vdots$ \\
\hline$\vdots$ & $\vdots$ & $\vdots$ & $\vdots$ & $\vdots$ & $\vdots$ \\
\hline 77 & 3 & 3 & 2 & 2 & 2 \\
\hline 78 & 3 & 3 & 2 & 3 & 3 \\
\hline 79 & 3 & 3 & 3 & 1 & 3 \\
\hline 80 & 3 & 3 & 3 & 2 & 3 \\
\hline 81 & 3 & 3 & 3 & 3 & 3 \\
\hline
\end{tabular}

Information :

$1=$ Low $/$ Near/Cool

$2=$ Medium/Normal

$3=\mathrm{Fast} / \mathrm{Far} / \mathrm{High} / \mathrm{Hot}$ 
The rule is continued until it satisfies all combinations of each variable with the $3^{\mathrm{n}}$ equation where $n$ is the number of variables. From these equations for 4 (four) input variables, namely Wind Speed, Visibility, Dew Point and Temperature, the rules obtained are 81 and the output rainfall.

\section{Results of Formation of Predicate Value ( $\alpha$ ) and $Z$ Value of Sugeno Method}

To form the value of using the MIN method, namely by taking the smallest value of each rule that has been made, which amounts to 81 rules. Furthermore, the 81 rules of the combination of four variables will then be calculated by the equation $\operatorname{IF}\left(\mathrm{x}_{1}\right.$ is $\left.A_{i}\right) o \ldots o\left(x_{n}\right.$ is $\mathrm{A}_{\mathrm{n}}$ ) THEN $\mathrm{z}=k$ where $\mathrm{A}_{\mathrm{n}}$ is the nth fuzzy set as the antecedent and $\mathrm{k}$ is a constant (firm) as the consequent to produce $\mathrm{z}$ values (light $=2$, medium $=6$ and heavy $=11$ ) or fuzzy numbers which will later be defuzzified to produce rainfall prediction output. Completely the predicate value $(\alpha)$ and $z$ value for the Sugeno model as shown in table 6 . The results of the predicate value $(\alpha)$ and $z$ value in the case of January 2007 Rainfall.

Table 6. Results of Formation of Predicate Value $(\alpha)$ and Z Value

\begin{tabular}{|c|c|}
\hline \multicolumn{2}{|r|}{ Fuzzy Rules } \\
\hline $\mathrm{R}_{1}$ & $\begin{array}{l}\text { IF wind_velocity LOW,AND visibility NEAR,AND dew_point LOW } \\
\text { AND,temperature COOL THEN rain LIGHT }\end{array}$ \\
\hline$\alpha$ - predicate $_{1}$ & $\begin{array}{l}\text { Min }\left(\mu_{\text {wind_velocity }} L O W[4,99] \cap \mu_{\text {visibility }} \operatorname{NEAR}[6,46] \cap \mu_{\text {dew_point }} \operatorname{LOW}[23,49] \cap\right. \\
\left.\mu_{\text {temperature }} \text { COOL }[26,66]\right) \\
\operatorname{Min}(0,70 ; 0 ; 0,77 ; 0,85) \\
=0\end{array}$ \\
\hline$Z_{1}$ & $=2$ \\
\hline $\mathrm{R}_{2}$ & $\begin{array}{l}\text { IF wind_velocity LOW,AND visibility NEAR,AND dew_point LOW } \\
\text { AND,temperature NORMAL THEN rain LIGHT }\end{array}$ \\
\hline$\alpha$-predicate 2 & $\begin{array}{l}\text { Min }\left(\mu_{\text {wind_velocity }} \operatorname{LOW}[4,99] \cap \mu_{\text {visibility }} \operatorname{NEAR}[6,46] \cap \mu_{\text {dew_point }} \operatorname{LOW}[23,49] \cap\right. \\
\left.\mu_{\text {temperature }} \text { NORMAL }[26,66]\right) \\
\operatorname{Min}(0,70 ; 0 ; 0,77 ; 0,15) \\
=0\end{array}$ \\
\hline $\mathrm{Z}_{2}$ & $=2$ \\
\hline $\mathrm{R}_{3}$ & $\begin{array}{l}\text { IF wind_velocity LOW,AND visibility NEAR,AND dew_point LOW } \\
\text { AND,temperature NORMAL THEN rain LIGHT }\end{array}$ \\
\hline$\alpha$-predicate 3 & $\begin{array}{l}\text { Min }\left(\mu_{\text {wind_velocity }} L O W[4,99] \cap \mu_{\text {visibility }} \operatorname{NEAR}[6,46] \cap \mu_{\text {dew_point }} \operatorname{LIGHT}[23,49] \cap\right. \\
\left.\mu_{\text {temperature }} \text { HOT }[26,66]\right) \\
\operatorname{Min}(0,70 ; 0 ; 0,77 ; 0,15 ; 0) \\
=0\end{array}$ \\
\hline$Z_{3}$ & $=2$ \\
\hline$\vdots$ & $\vdots$ \\
\hline$\vdots$ & $\vdots$ \\
\hline
\end{tabular}

Table 7. Results of Formation of Predicate Value $(\alpha)$ and Z Value (continued)

\begin{tabular}{|l|l|}
\hline \multicolumn{2}{|c|}{ Fuzzy Rules } \\
\hline$R_{81}$ & $\begin{array}{l}\text { IF wind_velocity LOW,AND visibility NEAR,AND dew_point LOW } \\
\text { AND,temperature COOL THEN rain LIGHT }\end{array}$ \\
\hline
\end{tabular}




\begin{tabular}{|c|l|}
\hline$\alpha$-predicate $_{81}$ & $\begin{array}{l}\text { Min }\left(\mu_{\text {wind_velocity }} \text { FAST }[0] \cap \mu_{\text {visibility }} \text { FAR[0,66] } \cap \mu_{\text {dew_point }} H I G H[0] \cap\right. \\
\mu_{\text {temperature HOT }[0])}\end{array}$ \\
& $\begin{array}{l}\text { Min }(0 ; 0,66 ; 0 ; 0) \\
=0\end{array}$ \\
\hline$Z_{81}$ & $=11$ \\
\hline
\end{tabular}

\section{Defuzzification}

The next step is to determine the decision linguistic variables of each rainfall rule, namely light has a value of 2, medium has a value of 6 and heavy has a value of 11 . Next calculates the defuzzification with an average (average):

$W A=\frac{\sum_{i}^{N} \alpha i Z i}{\sum_{i}^{N} \alpha i} \quad$, in the implication process of looking for the minimum value contained in the second process and determining the value of $\mathrm{z}_{\mathrm{i}}$, then we get the results of $\alpha_{\mathrm{i}}$ and $\mathrm{z}_{\mathrm{i}}$ from each rule in table 8, namely:

Table 8. Result of $\alpha_{\mathrm{i}}$ and $\mathrm{zi}_{\mathrm{i}}$

\begin{tabular}{|c|c|c|}
\hline No & ai value & $z$ value to- \\
\hline 1 & 0 & 2 \\
\hline 2 & 0 & 2 \\
\hline 3 & 0 & 2 \\
\hline 4 & 0 & 2 \\
\hline 5 & 0 & 2 \\
\hline 6 & 0 & 2 \\
\hline 7 & 0 & 2 \\
\hline 8 & 0 & 6 \\
\hline 9 & 0 & 6 \\
\hline 10 & 0,34 & 6 \\
\hline 11 & 0,15 & 6 \\
\hline 12 & 0 & 6 \\
\hline 13 & 0,23 & 6 \\
\hline 14 & 0,15 & 6 \\
\hline 15 & 0 & 11 \\
\hline 16 & 0 & 11 \\
\hline 17 & 0 & 11 \\
\hline 18 & 0 & 11 \\
\hline 19 & 0,66 & 11 \\
\hline 20 & 0,15 & 11 \\
\hline 21 & 0 & 11 \\
\hline 22 & 0,23 & 2 \\
\hline 23 & 0,15 & 2 \\
\hline 24 & 0 & 2 \\
\hline 25 & 0 & 2 \\
\hline 26 & 0 & 2 \\
\hline 27 & 0 & 2 \\
\hline 28 & 0 & 2 \\
\hline 29 & 0 & 6 \\
\hline
\end{tabular}




\begin{tabular}{|c|c|c|}
\hline 30 & 0 & 6 \\
\hline 31 & 0 & 6 \\
\hline 32 & 0 & 6 \\
\hline 33 & 0 & 6 \\
\hline 34 & 0 & 6 \\
\hline 35 & 0 & 6 \\
\hline 36 & 0 & 11 \\
\hline 37 & 0,3 & 11 \\
\hline 38 & 0,15 & 11 \\
\hline 39 & 0 & 11 \\
\hline 40 & 0,23 & 11 \\
\hline 41 & 0,15 & 11 \\
\hline 42 & 0 & 11 \\
\hline 43 & 0 & 2 \\
\hline 44 & 0 & 2 \\
\hline 45 & 0 & 2 \\
\hline 46 & 0,3 & 2 \\
\hline 47 & 0,15 & 2 \\
\hline 48 & 0 & 2 \\
\hline 49 & 0,23 & 2 \\
\hline 50 & 0,15 & 6 \\
\hline 51 & 0 & 6 \\
\hline 52 & 0 & 6 \\
\hline 53 & 0 & 6 \\
\hline 54 & 0 & 6 \\
\hline 55 & 0 & 6 \\
\hline 56 & 0 & 6 \\
\hline 57 & 0 & 11 \\
\hline 58 & 0 & 11 \\
\hline 59 & 0 & 11 \\
\hline 60 & 0 & 11 \\
\hline 61 & 0 & 11 \\
\hline 62 & 0 & 11 \\
\hline 63 & 0 & 11 \\
\hline 64 & 0 & 2 \\
\hline 65 & 0 & 2 \\
\hline 66 & 0 & 2 \\
\hline 67 & 0 & 2 \\
\hline 68 & 0 & 2 \\
\hline 69 & 0 & 2 \\
\hline 70 & 0 & 2 \\
\hline 71 & 0 & 6 \\
\hline 72 & 0 & 6 \\
\hline 73 & 0 & 6 \\
\hline
\end{tabular}




\begin{tabular}{|l|l|l|}
74 & 0 & 6 \\
\hline 75 & 0 & 6 \\
\hline 76 & 0 & 6 \\
\hline 77 & 0 & 6 \\
\hline 78 & 0 & 11 \\
\hline 79 & 0 & 11 \\
\hline 80 & 0 & 11 \\
\hline 81 & 0 & 11 \\
\hline
\end{tabular}

\section{Sugeno's Inference Fuzzy Defuzzification}

The last stage is defuzzification, changing the fuzzy value into a real value, from table 10 then entered into the average formula and the following results are obtained:

$$
\begin{aligned}
& z=\frac{\text { apred } 1 * z 1+\text { apred } 2 * z 2+\text { apred } 3 * z 3+\cdots+\text { apred } 81 * z 81}{\text { apred } 1+\text { apred } 2+\text { apred } 3+\cdots+\text { apred } 81} \\
& z=\frac{26,28}{3,72}=7,064
\end{aligned}
$$

By using the fuzzy inference system with the Sugeno method, the rainfall in January 2007 with wind speed 4.99 , visibility 6.46 , dew point 23.49 and temperature 26.66 has a rainfall defuzzification value of 7.064 with the linguistic variable being moderate. Next, the average rainfall data at Polonia stations from February to December 2007 was calculated using the Matlab2016a program and the results were obtained according to table 9 and Figure 6 below.

Table 9. Rainfall Data calculated by Matlab2016a

\begin{tabular}{|llllll|}
\hline Month & $\begin{array}{l}\text { Wind } \\
\text { Velocity } \\
(\mathbf{k m} / \mathbf{h o u r})\end{array}$ & $\begin{array}{l}\text { Visibiliy } \\
(\mathbf{k m})\end{array}$ & $\begin{array}{l}\text { Dew } \\
\text { Point } \\
(\mathbf{C})\end{array}$ & $\begin{array}{l}\text { Temperatur } \\
(\mathbf{C})\end{array}$ & $\begin{array}{l}\text { Rainfall } \\
(\mathbf{m m})\end{array}$ \\
\hline February & 5,86 & 5,56 & 23,09 & 27,32 & 11 \\
March & 6,09 & 6,51 & 23,28 & 28,15 & 5,11 \\
April & 4,65 & 6,58 & 23,90 & 27,79 & 2,69 \\
May & 5,94 & 7,63 & 23,94 & 27,65 & 6 \\
June & 4,72 & 7,12 & 24,09 & 27,91 & 2 \\
July & 4,44 & 6,38 & 23,87 & 27,30 & 3,83 \\
August & 5,85 & 7,22 & 23,49 & 27,18 & 2 \\
September & 6,00 & 7,86 & 23,59 & 27,07 & 2 \\
October & 4,85 & 7,90 & 23,67 & 26,67 & 6,39 \\
November & 5,35 & 7,67 & 23,50 & 26,59 & 3,61 \\
December & 5,10 & 7,52 & 23,39 & 26,58 & 8,38 \\
\hline
\end{tabular}


8. Randwick International of Social Science Journal

ISSN Online: 2722-5674 - ISSN Print: 2722-5666

Yuan Ardi, Syahril Effendi, Erna Budhiarti Nababan

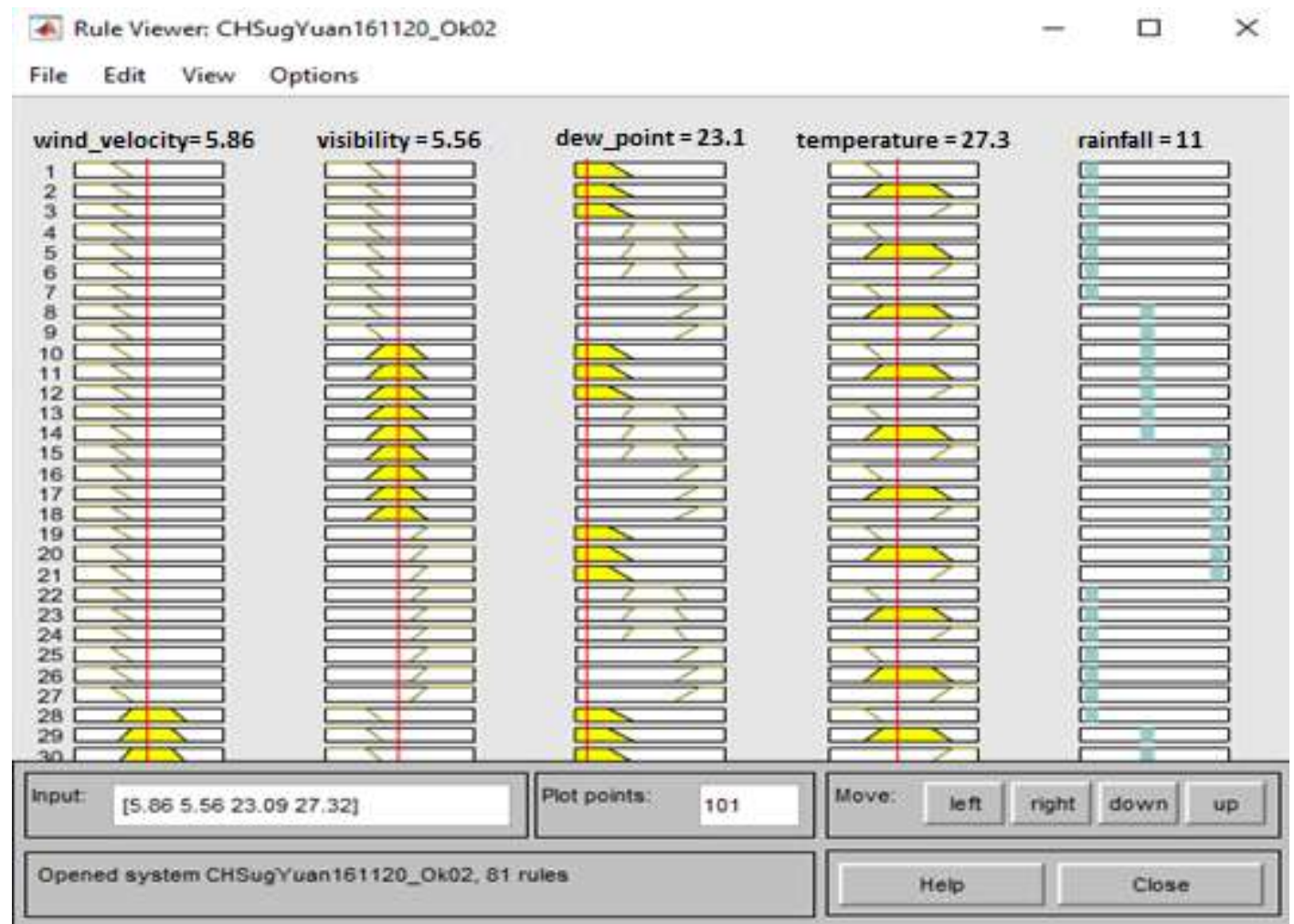

Figure 5. Rainfall Rule Viewer Results, February 2007

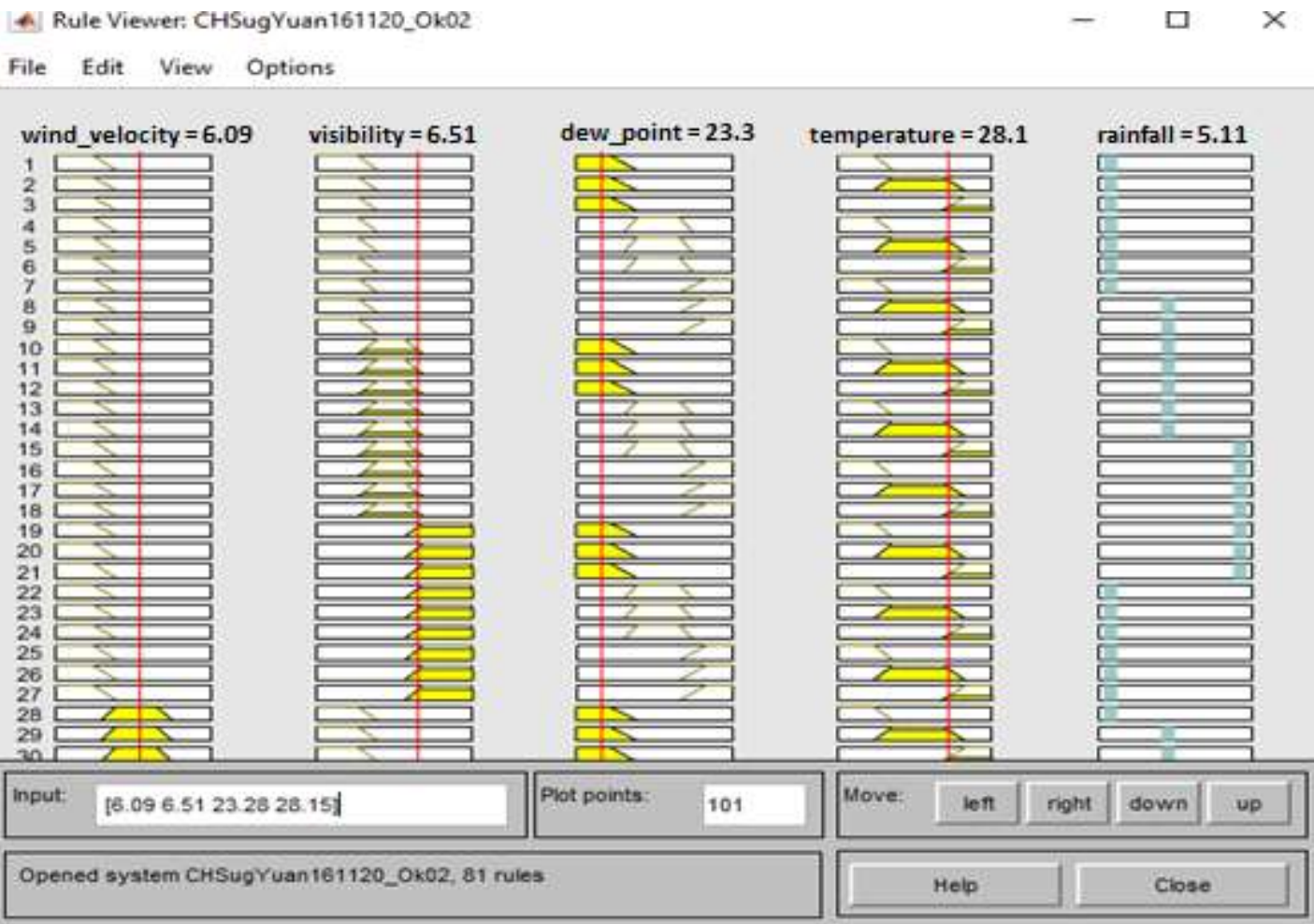

Figure 6. Rainfall Rule Viewer Results, March 2007 


\section{Formation of basic rules (implications) of Fuzzy Mamdani}

After creating fuzzy sets and fuzzy inputs as well as forming membership degrees, then the basic rules of fuzzy mamdani are formed using the mamdani fuzzy model, in general the form of the mamdani fuzzy model is

IF $\mathrm{x}_{1}$ is $\mathrm{A}_{1}$ AND ... AND $\mathrm{x}_{\mathrm{n}}$ is $\mathrm{A}_{\mathrm{n}}$ THEN $\mathrm{y}$ is $\mathrm{B}$

\section{Mamdani Fuzzy Rules Composition}

Combining all input variables with t-norm $<$ all input variables with t-norm, is a slice operation on fuzzy sets. The implication function used in this study is min or multiconjunctive with AND link. There is a new set of component rules $X_{R}$, where $R=1,2,3, \ldots, n$. as follows $\mathrm{x}=\mathrm{x}_{1}$ AND $\mathrm{x}_{2}$ AND ... AND $\mathrm{x}_{\mathrm{n}}$, defined by the membership function $\mu_{\mathrm{x}}(\mathrm{x})=$ $\min \left(\left(\mu_{\mathrm{x} 1}(\mathrm{x}), \mu_{\mathrm{x} 2}(\mathrm{x}), \ldots, \mu_{\mathrm{xn}}(\mathrm{x})\right)\right.$ for $\mathrm{x}$

\section{Mamdani Defuzzificationzz}

Change the fuzzy output to a firm value based on a predetermined membership function. The input of the defuzzification process is a set obtained from the composition of fuzzy rules, while the resulting output is a fuzzy set domain data number. The defuzzification used is the Centroid Method or it can also be called COA. COA is used in taking the center point ( $\mathrm{z}^{*}$ ) in the fuzzy area, with the following equation:

$Z^{*}=\frac{\int z \mu(z) d z}{\int \mu(z) d z}$

Next is the rainfall data at Polonia station from January to December 2007 using Matlab2016a software and the results are in accordance with Table 10 and figure 8 to figure 9

Table 10. Rainfall Data based on Matlab2016a Mamdani Method

\begin{tabular}{|lccccc|}
\hline Month & $\begin{array}{c}\text { Wind } \\
\text { Velocity } \\
(\mathbf{k m} / \text { hour })\end{array}$ & $\begin{array}{c}\text { Visibility } \\
\mathbf{( k m )}\end{array}$ & $\begin{array}{c}\text { Dew } \\
\text { Point } \\
(\mathbf{C})\end{array}$ & $\begin{array}{c}\text { Temperature } \\
(\mathbf{C})\end{array}$ & $\begin{array}{c}\text { Rainfall } \\
(\mathbf{m m})\end{array}$ \\
\hline January & 4,99 & 6,46 & 23,49 & 26,66 & 9,98 \\
February & 5,86 & 5,56 & 23,09 & 27,32 & 12,40 \\
March & 6,09 & 6,51 & 23,28 & 28,15 & 5,30 \\
April & 4,65 & 6,58 & 23,90 & 27,79 & 3,38 \\
May & 5,94 & 7,63 & 23,94 & 27,65 & 7,00 \\
June & 4,72 & 7,12 & 24,09 & 27,91 & 2,00 \\
July & 4,44 & 6,38 & 23,87 & 27,30 & 5,20 \\
August & 5,85 & 7,22 & 23,49 & 27,18 & 2,10 \\
September & 6,00 & 7,86 & 23,59 & 27,07 & 2,21 \\
October & 4,85 & 7,90 & 23,67 & 26,67 & 7,34 \\
November & 5,35 & 7,67 & 23,50 & 26,59 & 4,28 \\
December & 5,10 & 7,52 & 23,39 & 26,58 & 9,45 \\
\hline
\end{tabular}


8. Randwick International of Social Science Journal

ISSN Online: 2722-5674 - ISSN Print: 2722-5666

Yuan Ardi, Syahril Effendi, Erna Budhiarti Nababan

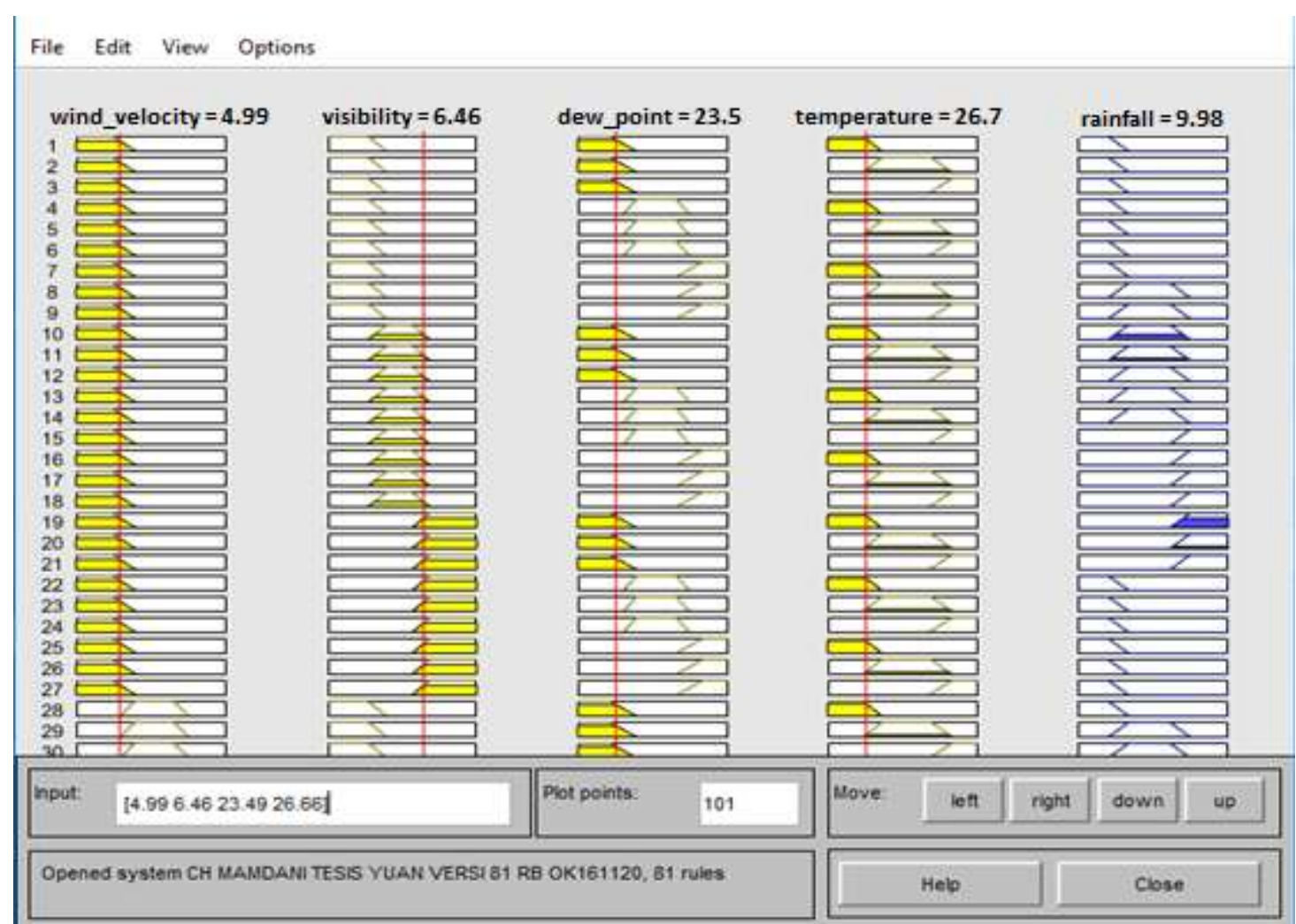

Figure 7. Rainfall Rule Viewer Results Mamdani, January 2007

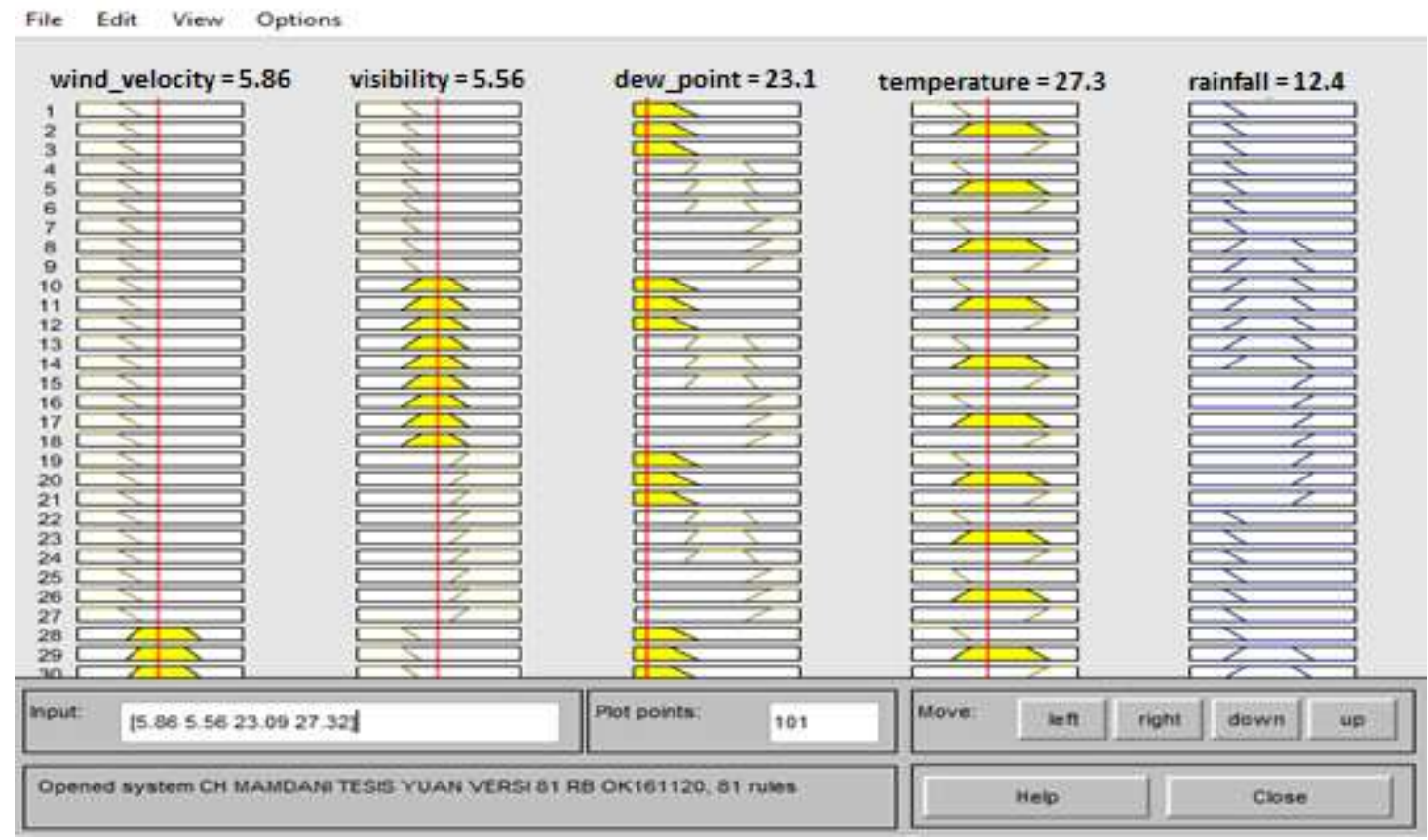

Figure 8. Rainfall Rule Viewer Results Mamdani, February 2007 


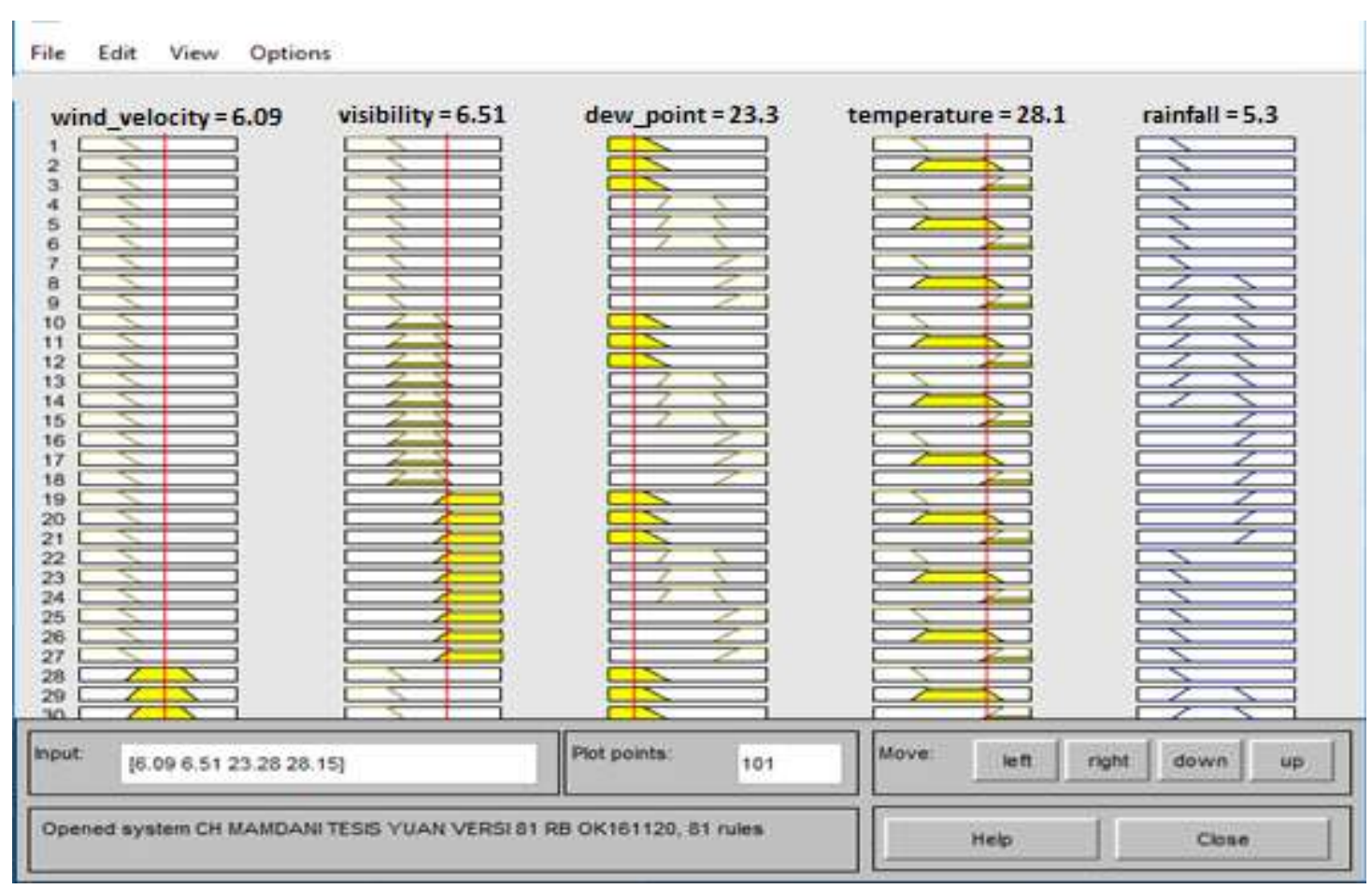

Figure 9. Rainfall Rule Viewer Results Mamdani, March 2007

\section{CONCLUSION}

Based on the results of the analysis and discussion that has been done, the authors conclude this research, that two methods used to predict rainfall at the Polonia station, Sugeno fuzzy inference produces an error rate of 1.33 percent while Mamdani's fuzzy inference produces an error rate of 1.45 percent based on the results of calculations using Matlab2016a. Each error is still limited to an error tolerance of no more than 10 percent, so the prediction is still considered accurate. The accuracy of the Sugeno fuzzy inference method in this study is better than the Mamdani inference model. By looking at the difference in the actual data and the Fuzzy Inference System with the Sugeno method and the Mamdani method, it is very suitable for the estimation of rainfall in this study.

The author suggests in the development of this research that, to predict rainfall at the Polonia station, use the Sugeno fuzzy inference method and Mamdani fuzzy inference using wind speed, visibility, dew point and temperature variables which are input data for rainfall prediction, due to rainfall. It is not only determined by wind speed, visibility, dew point and temperature, but the factor of duration of sunshine and total cloud layer can also affect the prediction of rainfall. Therefore, in order for this research to produce more accurate results, it is necessary to apply/use additional input variables such as the length of sunlight, pressure on sea level and total cloud layer and research using other fuzzy inference methods such as interval type 2 fuzzy systems

\section{REFERENCES}

Akash D Dubey. (2015). Artificial Neural Network Models for Rainfall Prediction in Pondicherry. International Journal of Computer Applications (0975-8887) Vol.2(3).

Batra,G. \& Trivedi, M. (2013). A Fuzzy approach for software effort estimation. International Jurnal on Cybernetic \& Informatic 2 (1). 9-15.

Cox, Earl. (1994). The Fuzzy System Handbook. Massachusetts; Academic Press-Inc. 
Ebadi M.A et.al. (2011). Evolving Genetic Algorithm, Fuzzy Logic and Kalman Filter For Prediction of Asphaltene Precipitation due to Natural Depletion. International Journal of Computer Application. 35 (11).12-16.

Fallah Ghalhary et.al. (2009). Annual Rainfall Forecasting by Using Mamdani Fuzzy Inference System. Research Journal of Environment Sciences. Vo. 3 (4).pp 400-413.

Hossein, Zadeh et.al. (2011). Development of a Fuzzy Model to Determine the Optimum Sher Strength of Wheat Stem. International Journal of Computer Science and Telecommunications. 2(4).pp 56-60.

Indrabayu, Nadjamuddin Harun et.al (2013). A New Approach of System for Rainfall Prediction Based on Data Series. International Journal of Enggineering Research and Applications (IJERA).Vol.3 (2).pp.1805-1809.

Iswari, L. \& Wahid, F. (2005). Alat Bantu Sistem inferensi Fizzy Metode Sugeno Orde Satu. Seminar Nasional Aplikasi Teknologi Informasi. pp,1-3.

Kaur, A. \& Kaur, A (2012). Comparison Of Mamdani-Type and Sugeno-Type Fuzzy Inference Systems for Air Conditioning System. International Jurnal of Soft Computing anf Engineering2(2):323-325.

Klir, G,J, \& Yuan, B. (1995). Fuzzy Sets and Fuzzy Logic Theory And Application PrienticHall Inc. United State of America.

Kusumadewi, S., \& Purnomo, H. (2010). Aplikasi Logika Fuzzy untuk Pendukung Keputusan Edisi 2. Yogyakarta. Graha Ilmu.

Mayilvaganan M. Kavitha et.al. (2011). ANN and Fuzzy Logic Models for the Prediction of groundwater level of a watershed.International Journal on Computer Science and Engineering. Vol.3: 2523-2530.

Nasr, A.S. Rezal, M. \& Barmaki, M.D. (2012). Analysis of groundwater quality using mamdani fuzzy inference system (mfis) in yazd province, iran. International Journal of Computer Applications.95(7):45-53.

Nasution, H. (2012). Implementasi Logika Fuzzy pada Sistem Kecerdasan Buatan. Journal ELKHA4(2):4-8

Nezhad, Q.A., Zand, J.P \& Hosaini, S.S. (2013). An investigation on fuzzy logic controllers (takagi-sugeno \& mamdani) in inverse pendulum system. International Journal of Fuzzy Logic Systems3(3):1-14.

Pallavi et.al, (2016). Review on Rainfall Forecasting Using Different Techniques and Algorithms.International Journal of Innovative Research in Computer and Communication Enginerring.Vol.4(3):2901-2902.

Sivarao, Breven, P., El-Thyeb, N.S.M \& Vengkatesh, V.C. (2009). GUI Based Mamdani Fuzzy Inference System Modeling To Predict Surface Roughness in Laser Machining. International Jurnal of Electrical \& Computer Sciences IJECS-IJENS9(9):37-43

Sofwan, A. (2005). Penerapan Fuzzy Logic pada Sistem Pengaturan Jumlah Air Berdasrkan Suhu dan Kelembaban.Seminar Nasional Aplikasi Teknologi Informasi.pp. C-89-C-83.

Sundaravalli, N. et.al (2016). A Study \& Survey on Rainfall Prediction And Production of Crops Using Data Mining Techniques. International Research Journal of Engineering and Technology.1269-1274

Susilo, F. (2006). Himpunan dan Logika Kabur serta Aplikasinya, Yogyakarta : Graha Ilmu. Suwandi, Irawan, M.I \& Muklish, I. (2011). Aplikasi Sistem Inferensi Fuzzy Metode Sugeno Dalam Memperkirakan Produksi Air Mineral Dalam Kemasan. Seminar Nasional Penelitian, Pendidikan dan Penerapan MIP.pp-MI-M9.

The National Climate Data Centre. (NCDC). In Asheville, Nort Caroline, USA.http://www7.ncdc.noaa.gov/cdo.

Zadeh, L.A. (1965). Fuzzy Sets. Information and Control 8.338-353. 
Zadeh, L.A. (1973). Outline OF A New Approach To The Analysis Of Complex Systems and Decision Processes. IEEE Transsaction on Systems, Man, and Cybernetic 3: 28-44.

Zadeh, L.A. (1990). Fuzzy Sets And Systems. International Jurnal of General Systems. 17 (2):129-138.

Zadeh, L.A. (2004). Fuzzy Logic Systems : Origin, Concepts, And Trends. Computer Science Division Departement of EECS UC Berkeley. 1-138 